\title{
Life Cycle Assessment of a Plant-Based, Regionally Marketed Shampoo and Analysis of Refill Options
}

\author{
Hanna Kröhnert and Matthias Stucki *(D) \\ Institute of Natural Resource Sciences, Life Sciences and Facility Management, Zurich University of Applied \\ Sciences (ZHAW), CH-8820 Wädenswil, Switzerland; hanna.kroehnert@gmail.com \\ * Correspondence: matthias.stucki@zhaw.ch
}

Citation: Kröhnert, H.; Stucki, M. Life Cycle Assessment of a Plant-Based, Regionally Marketed Shampoo and Analysis of Refill Options. Sustainability 2021, 13, 8478. https://doi.org/10.3390/su13158478

Academic Editor: Silvia Fiore

Received: 9 June 2021

Accepted: 22 July 2021

Published: 29 July 2021

Publisher's Note: MDPI stays neutral with regard to jurisdictional claims in published maps and institutional affiliations.

Copyright: (c) 2021 by the authors. Licensee MDPI, Basel, Switzerland. This article is an open access article distributed under the terms and conditions of the Creative Commons Attribution (CC BY) license (https:// creativecommons.org/licenses/by/ $4.0 /)$.

\begin{abstract}
The environmental impact of a plant-based shampoo produced and marketed in Zurich, Switzerland, was analyzed using the life cycle assessment method. Beside the identification of environmental hotspots and mitigation possibilities, the focus of the study was on the analysis and comparison of different refill offers. The results of the study show that one hair wash using the investigated shampoo is related to greenhouse gas emissions of $161 \mathrm{~g} \mathrm{CO}_{2} \mathrm{eq}$. For all investigated impact categories, the use phase represents the dominant life stage, except for land use, which is dominated by the production of the purely plant-based shampoo ingredients. The environmental impact related to the use phase is highly sensitive on the consumers' showering habits, such as water consumption and water temperature, due to predominantly fossil-based heating in Zurich. On the producer's side, a switch to renewable energy sources both for heating and electricity is identified as most effective measure to reduce the environmental impact of the manufacturing phase. As to the product end-of-life, the results suggest that emissions of the shampoo ingredients after wastewater treatment have a negligible impact on freshwater ecotoxicity. In this context, a need for further research is identified with respect to characterization factors and specific removal rates in wastewater treatment plants. From a life cycle perspective, packaging production and disposal have rather low contributions. Offering refill possibilities can reduce the packaging related contributions by several percentage points, however, higher mitigation potentials are found for use phase and manufacturing.
\end{abstract}

Keywords: shampoo; natural ingredients; packaging; refill; LCA; environmental impact

\section{Introduction}

Shampoo represents one of the most common personal care products: In European households, shampoo is used with an average application frequency of two to three times per week [1], amounting to about $2 \mathrm{~kg}$ of shampoo used per person each year [2]. While previously rather neglected as a research topic [3], the environmental impact of personal care products from a life cycle perspective has received increasing attention in the last decade. However, publications on life cycle assessment (LCA) of shampoo using a cradleto-grave approach are still rare.

At the European level, comprehensive LCA studies on representative products were conducted by Cosmetics Europe and Quantis [4,5] and by the Joined Research Centre of the European Commission [6], which considered ingredients compositions and packaging solutions most widely used on the European market. The two studies found various environmental hotspots for shampoo: climate change, water resource depletion, mineral and fossil resource depletion, eutrophication, particulate matter, human toxicity, and freshwater ecotoxicity. While the results for freshwater ecotoxicity are almost entirely dominated by the product disposal via wastewater treatment, the studies show that all other ecological hotspots contain a major contribution from the use stage of the shampoo, specifically the use of hot water while showering. In fact, the extent of the environmental impact of a shampoo is very sensitive towards consumer habits such as the water temperature and the 
water consumption while showering. In addition, the energy mix assumed for the heating system has a strong impact on the results [4].

Relevant processes in the producer's area of influence are for example the choice of ingredients and the choice of packaging material [6]. Regarding the ingredients of a shampoo, the origin of the raw materials plays an important role, especially for surfactants, which form the main component of shampoo, apart from water. Surfactants in conventional shampoo formulas are typically produced on a petro-chemical basis, like sodium laureth sulfate. Despite regulations regarding toxicity and concentration levels of surfactants, there are still concerns about their biodegradability and eco-friendliness [7]. The growing ecological awareness of consumers has prompted an increased market share of bio-based surfactants because of their biodegradability and biocompatibility properties [8]. Examples of biogenic resources for surfactants are palm oil and rape seed oil. Bio-based surfactants can help to reduce the usage of fossil resources. At the same time, the cultivation of oil plants generally results in higher eutrophication, in a higher land use and, depending on the oil plant and agricultural practice, even in a higher global warming potential [9].

As most shampoos are sold in plastic bottles, there is a trend towards replacing fossilbased plastic by materials based on biogenic resources [6]. However, the use of bio-based plastic is not without controversy, mainly because of land use and potential competition to food production connected to agro-based feedstocks [10].

Refill packages represent an effective measure to reduce waste, not only for shampoo, but also for soaps and household detergents [11]. According to Koehler and Wildbolz [3], the overall environmental impact of shampoo originally sold in plastic bottles could be reduced by more than $10 \%$ by selling refill portions in stand-up pouches made of plastic. By now, refill pouches belong to the standard product range of supermarkets and are well accepted by costumers, also because unit prices are normally lower for refill products [11].

A different approach that aims at waste prevention is that consumers fill their own containers from bulk dispensers directly in the stores. Bulk dispensers are normally avoided by big retailers, as they require a change in logistics as well as a substantial behavioral change from consumers [12,13]. Nonetheless, the number of small eco-oriented zerowaste stores addressing environmentally conscious costumers surged in the last decade in Europe [14]. A survey by Branska et al. [14] showed that frequent costumers of zero-waste stores do not primarily expect lower prices, but rather appreciate the opportunity to buy high quality products and to support local producers. In this context, zero-waste stores represent a market opportunity for regional producers.

The importance of waste prevention has an additional dimension for developing regions that do not have an established waste collection system, and that suffer from massive littering. Haerulloh and Hiwari [15], for example, propose the launch of bulk stores with refill possibilities for a remote coastal region in Indonesia in order to rise environmental awareness and to fight marine pollution from household waste.

As alternative to commonly used plastic bottles, glass bottles are often regarded as environmentally friendly by consumers [16]. In contrast to this perception, the environmental performance of glass is strongly compromised by the high energy demand for the production and the high fuel consumption for transportation, especially compared to light plastic materials with high ratios of recycled materials [17]. Nonetheless, glass bottles in combination with reuse options can make sense on a local scale with short transportation distances, as shown by Ferrara and De Feo [18].

The general findings of LCA studies on representative shampoo formulas can be applied to a wide range of shampoos, e.g., the sensitivity towards the consumers' showering habits and the trade-off considerations to be made concerning raw materials both for ingredients and packaging materials. At the same time, the results show that productspecific studies should be conducted in order to derive effective recommendations for the reductions of the environmental impact of individual shampoos. This is particularly true for niche products, such as eco-oriented products from small producers, which often use neither main-stream ingredients nor main-stream packaging solutions. 
This paper summarizes the results of an LCA study carried out for such a product: a natural shampoo that is produced by a small manufactory and that is sold in glass bottles mainly on a regional market in Switzerland. The goals of the study were (a) to quantify the environmental impact of the shampoo and to deduce recommendations for further improvements, mainly from the producer's perspective, and (b) evaluate and compare four specific packaging scenarios, taking into account not only the waste reduction potential but also other relevant environmental indicators such as global warming potential and primary energy demand.

\section{Methods}

The environmental impact of the shampoo and of the different packaging scenarios was derived with the life cycle assessment method following the ISO 14040 standard [19], taking into account the resource demand and the emissions along the entire life cycle of the shampoo (cradle-to-grave). The analysis was carried out using the software SimaPro v9 [20].

\subsection{Functional Unit and Investigated Product System}

Analogously to the study carried out by Quantis [4], the life cycle of shampoo was divided into seven stages, as shown in Figure 1, which also summarizes the processes that were included in each life stage. The functional unit (FU) of the investigated product system consisted of one hair wash. Geographically, the study was conducted for Zurich, Switzerland, where the shampoo was produced, marketed, used, and disposed. With respect to the packaging material and the ingredients of the shampoo, the countries of extraction, cultivation, and production, respectively, were considered as well. The study was carried out in 2020 with the most current data being used.

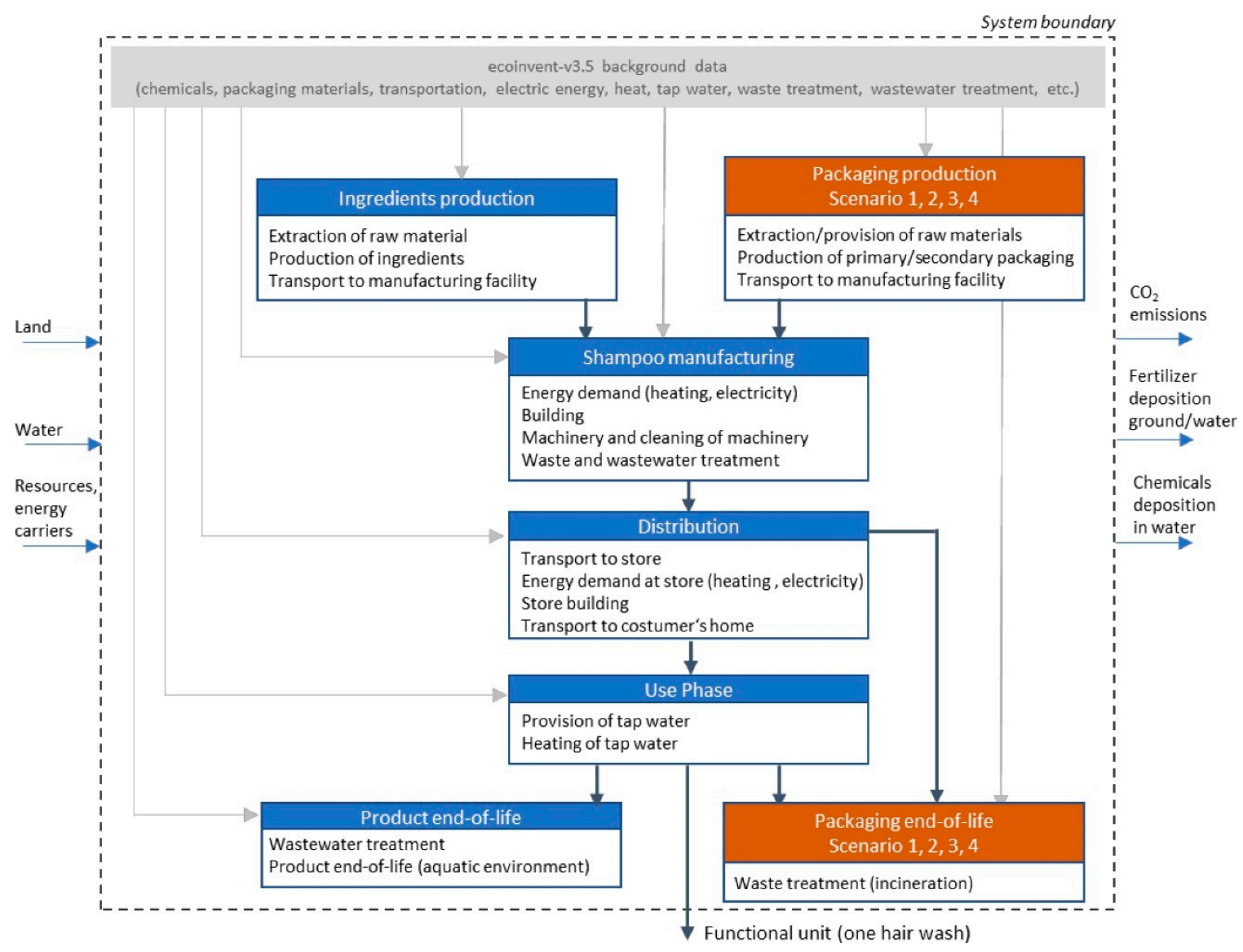

Figure 1. Investigated product system for one hair wash and considered processes for each life stage; packaging-dependent life phases are highlighted in orange. 
Four scenarios were compared regarding the packaging of the shampoo. The life stages that were influenced by the choice of scenario were packaging production and packaging end-of-life, and to a smaller extent product distribution.

Scenario 1 represented the basic version in which the shampoo was sold in a $500 \mathrm{~mL}$ glass bottle, including a dispenser pump made of polyethylene (PE) and polypropylene (PP), and packed in a small carton box as part of the primary packaging;

Scenario 2 represented an already existing refill option, which allowed customers to refill their own bottles or containers in company-owned local shops out of single-use $5 \mathrm{~L}$ canisters made of tin;

Scenario 3 described a potential alternative to the existing refill option, assuming the use of single-use $25 \mathrm{~L}$ plastic canisters made from PE for refill;

Scenario 4 described another potential alternative to the existing refill option, selling refill portions in $500 \mathrm{~mL}$ stand-up pouches made from polyethylene terephthalate (PET).

\subsection{Data Collection and Life Cycle Inventory}

The reference flow, i.e., the amount of shampoo needed to fulfill the functional unit of one hair wash, was set to $9.5 \mathrm{~g}$ shampoo. This amount referred to the average shampoo dosage per application by German consumers [21], which was used as an approximation due to the lack of specific data for Switzerland.

Foreground data concerning the production of ingredients and packaging as well as manufacturing and distribution were collected primarily via questionnaires from the producer of the shampoo. This data comprised shampoo formula, packaging compositions, transportation means and distances, building dimensions, production and sales volumes, as well as energy consumption and energy sources. Foreground data related to the use phase and the end-of-life stages were mainly taken from published values. In case of data gaps, assumptions were made based on published values and own estimations. The ecoinventv3.5 database [22] was used to model background inventory data, such as chemicals, heat, electricity, tap water, machinery, buildings, packaging materials, transportation, and waste treatment.

Table 1 summarizes the main ingredients of the shampoo and the corresponding raw materials. The production of the ingredients was modelled via ecoinvent background data, and, when possible, taking into account the origin of the raw materials. While the exact formula of the shampoo was known, approximations had to be made when assigning each ingredient to a suitable ecoinvent dataset. The investigated shampoo contained more than ten difference essential oils. For the sake of simplification, all essential oils were modelled in a combined way as orange oil, which was the principal fragrance of the shampoo and for which a detailed life cycle inventory was available in literature [23].

Table 1. Main composition of investigated shampoo and corresponding raw materials; the listed ingredients account for more than $99 \mathrm{w} \%$.

\begin{tabular}{|c|c|c|c|}
\hline Ingredient & Function & Composition & Raw Materials \\
\hline Deionized water & & {$[70-80 \mathrm{w} \%]$} & tap water \\
\hline Propanediol & humectant & {$[5-10 \mathrm{w} \%]$} & maize \\
\hline Coco-Glucoside & surfactant & {$[5-10 \mathrm{w} \%]$} & maize; coconut \\
\hline (Di)Sodium Cocoyl Glutamate & surfactant & {$[1-5 \mathrm{w} \%]$} & coconut; sugar beet/wheat \\
\hline Glycerin & $\begin{array}{l}\text { emollient, } \\
\text { conditioning }\end{array}$ & {$[1-5 \mathrm{w} \%]$} & maize/sugar beet/soybean \\
\hline Sodium PCA & conditioning & {$[1-5 \mathrm{w} \%]$} & sugar cane \\
\hline Sodium Levulinate & preservative & {$[0-1 \mathrm{w} \%]$} & cellulose \\
\hline Alcohol & preservative & {$[0-1 \mathrm{w} \%]$} & sugar cane/sugar beet \\
\hline Citric Acid & buffering & {$[0-1 \mathrm{w} \%]$} & - \\
\hline Essential oils and plan extracts & perfuming & {$[0-0.5 \mathrm{w} \%]$} & oranges \\
\hline
\end{tabular}


Apart from water, all ingredients of the shampoo were bought from suppliers, mainly abroad from Switzerland. The transport from the suppliers to the shampoo manufacturing site was modelled individually for each ingredient based on the distances determined with the web mapping service Google Maps [24].

The composition of materials for different packaging scenarios is given in Table 2. Again, the transport from the suppliers to the shampoo manufacturing site was modelled individually for each component based on the distances determined with Google Maps. Following the applied cut-off approach described below, the study did not include the costumer-owned containers that are refilled with shampoo in scenario 2 to 4 . However, rinsing of containers with warm water prior to the refill was considered, assuming that each container was rinsed twice with hot water heated up from 15 to $50^{\circ} \mathrm{C}$, which led to a water demand of $2 \mathrm{~L}$ and an energy demand of $0.3 \mathrm{MJ}$ per kg refilled shampoo.

Table 2. Characteristics of four investigated packaging scenarios for shampoo; weight specifications refer to the functional unit of $9.5 \mathrm{~g}$ shampoo.

\begin{tabular}{cccc}
\hline Component & Material & $\begin{array}{c}\text { Content of } \\
\text { Recycled Material }\end{array}$ & Weight per FU \\
\hline Scenario 1 & & & \\
Bottle (500 mL) & brown glass & $69 \%$ & $5.1 \mathrm{~g}$ \\
Dispenser pump & PE/PP & $0 \%$ & $0.21 \mathrm{~g}$ \\
Covering box & cardboard & $95 \%$ & $0.54 \mathrm{~g}$ \\
Box (secondary packaging) & cardboard & $95 \%$ & $0.92 \mathrm{~g}$ \\
\hline Scenario 2 & & & \\
Canister (5 L) & tinplate & $75 \%$ & $0.83 \mathrm{~g}$ \\
Box (secondary packaging) & cardboard & $95 \%$ & $0.51 \mathrm{~g}$ \\
\hline Scenario 3 & & & $0.45 \mathrm{~g}$ \\
Canister (25 L) & PE & $0 \%$ & \\
\hline Scenario 4 & & $0.19 \mathrm{~g}$ \\
Stand-up pouch (500 mL) & PET & $95 \%$ & $0.46 \mathrm{~g}$ \\
\hline Box (secondary packaging) & cardboard & & \\
\hline
\end{tabular}

Regarding the manufacturing phase, the energy demand both for heating and electricity was derived based on the total consumption at the manufacturing site for 2019 and the mass of the total production volume of the same year. This resulted in $0.26 \mathrm{MJ}$ heating energy per FU based on oil and 23.4 Wh per FU based on the Swiss market mix for electricity. The building, including office spaces, was modelled using a generic ecoinvent dataset for multistory buildings. As copper appeared to be overestimated within the generic dataset, it was excluded for this study to avoid unrealistically high contributions to the results, especially regarding freshwater ecotoxicity. Based on actual building dimensions and total production volume for 2019 , a cubature of $22.5 \mathrm{~cm}^{3}$ per FU was derived, assuming a building lifetime of 80 years. A shampoo loss of $2.5 \%$ during manufacturing was taken into account, based on estimations by the producer.

The shampoo being marketed on a local scale, a relatively short transportation distance of $18 \mathrm{~km}$ from the manufacturing site to the producer-owned store was modelled for distribution. Analogously to the manufacturing phase, the building and energy demand of the store were derived based on actual building dimensions, the total energy consumption at the store for 2019 as well as the total sales volume for 2019. Here, the results were a heating energy of $0.05 \mathrm{MJ}$ per FU based on natural gas and an electricity consumption of 2.2 Wh per FU using an electricity mix mainly based on hydropower [25]. The corresponding value for building cubature was $2.5 \mathrm{~cm}^{3}$ per FU. The transportation to the consumer's home was assumed to be undertaken by public transport ( $5 \mathrm{~km}$ with trolley bus), considering that the shampoo was sold mainly in urban stores with little parking possibilities and generally good connection to public transport. 
For the use phase, a tap water consumption of $15 \mathrm{~L}$ per hair wash was assumed, heated up from $15^{\circ} \mathrm{C}$ to $38{ }^{\circ} \mathrm{C}$ with $90 \%$ energy efficiency, which resulted in an energy demand of 1.6 MJ per FU [4]. The energy mix for heating water (both for showering and for rinsing containers to be refilled) was set to $49.9 \%$ natural gas, $27.2 \%$ oil, $15.8 \%$ district heating, $6 \%$ heat pump, $0.1 \%$ other sources, representing the energy mix of private households in Zurich [26]. The impact of water temperature and water quantity as well as energy mix for heating water on the results of the life cycle assessment was investigated with the help of sensitivity analyses.

Considering the household connectivity of nearly $100 \%$ in Switzerland, all wastewater was assumed to be purified in a municipal wastewater treatment plant (WWTP). A large WWTP was modelled with an average capacity size of 233,000 per-capita-equivalents (PCE) and a three stage wastewater treatment (mechanical, biological, chemical), including sludge fermentation [27]. The fermented sludge was assumed to be disposed via incineration. The inventory of the wastewater treatment was assessed via an excel-based inventory tool taking into account the wastewater volume and the chemical composition of the shampoo [27]. To assess human toxicity and freshwater ecotoxicity due emissions of shampoo ingredients after wastewater treatment, an average removal rate of $99.9 \%$ for fragrances and 90\% for other ingredients was applied [5].

For the packaging end-of-life, following recycling rates were considered: $94 \%$ for glass, $82 \%$ for cardboard, and $94 \%$ for tinplate [28]. Municipal solid waste incineration was applied to the non-recycled materials.

A detailed list of the inventory of all life stages as well as the used ecoinvent datasets can be found in the supplementary material S1 of this paper.

\subsection{Allocation and Recycling Processes}

The product system as shown in Figure 1 contained several multi-product processes, which required an allocation of resources and emissions. The environmental burdens of manufacturing building, shop building as well as the energy demand (heat and electricity) were allocated based on the mass of production and sales volume, respectively. The life cycle inventory of orange oil production was taken from a study by Beccali et al. [23]. Here, the environmental impact of orange cultivation was allocated to two outputs, orange oil and orange juice, following a combined mass and economic criterion. With respect to the use phase, typical consumption patterns in Switzerland show a water consumption of $40 \mathrm{~L}$ for each shower [29]. As showering often serves multiple purposes, such as skin cleansing, hair washing and relaxation, $15 \mathrm{~L}$ of warm water was attributed to one hair wash, following the approach by Quantis [5].

Regarding ecoinvent background datasets, the system model allocation, recycled content cut-off was used, in which the subdivision of multi-product activities was done by allocation based on physical properties, economic revenue, mass, or other properties. With respect to the packaging material, the cut-off system model implicated that the use of recycled material did not lead to any environmental burden connected to the primary extraction of raw materials. Accordingly, no environmental credit was granted for reuse and recycling of the packaging materials at the end-of-life stage.

\subsection{Impact Assessment}

The following impact categories were considered on midpoint-level: global warming potential (GWP) on a 100a horizon [30]; resource use of non-renewable energy carries [31], particulate matter [32], land use [33], and freshwater eutrophication [34] as implemented in the European Footprint (EF) method; freshwater ecotoxicity [35] and human toxicity [35] as implemented in the USEtox method, using both recommended and interim characterization factors. Despite representing one of the ecological hotspots of shampoo, water scarcity was omitted as impact indicator, as it was not consistently implemented in the ecoinvent-v3.5 database within SimaPro at the time the study was carried out. Resource use of minerals and metals [31] was taken into account for the comparison of packaging scenarios, as 
this indicator proved to be relevant with respect to the investigated tinplate canister of scenario 2. Because of high uncertainties within most methods, long-term emissions were excluded in the impact assessment for all midpoint indicators.

In addition to the eight midpoint-indicators, the overall environmental impact as a single-score-indicator was included in the impact assessment, expressed in eco-points according to the ecological scarcity method [36], including long-term emissions. The ecological scarcity method aggregates 19 environmental impact categories to one single indicator using weighting factors on a distance-to-target principle. In the Swiss version of the method, weighting factors are derived by comparing current emissions to national emission targets and to international targets supported by Switzerland.

\section{Results}

\subsection{Life Cycle Environmental Impact}

According to the life cycle assessment carried out in this study, one hair wash using the investigated shampoo is connected to greenhouse gas emissions of $161 \mathrm{~g} \mathrm{CO}_{2} \mathrm{eq}$ and a resource use of non-renewable energy carriers equivalent to $2.5 \mathrm{MJ}$, based on the IPCC 2013 100a model and the EF method, respectively. Figure 2 shows the relative contributions from different life phases to all considered impact indicators.

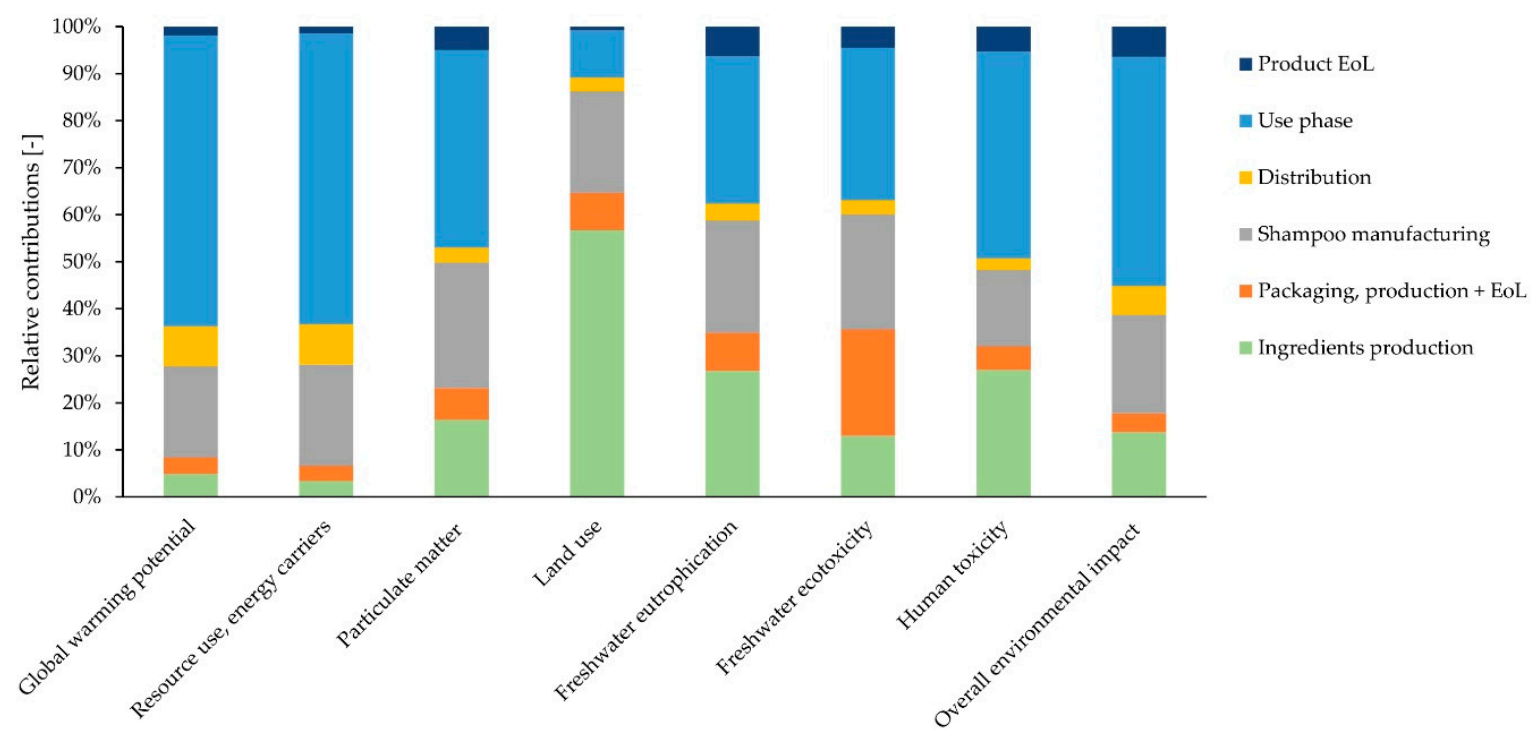

Figure 2. Relative environmental impact from life phases of shampoo, assessed with IPCC 2013 100a (GWP), the EF method (resource use, particulate matter, land use, freshwater eutrophication), the USEtox method including recommended and interim characterization factors (freshwater ecotoxicity, human toxicity), and the ecological scarcity method (overall environmental impact).

The use phase is the most relevant life stage for all impact categories, except for land use, with the highest contributions of more than $60 \%$ to GWP and to resource use of energy carriers. The manufacturing phase is another relevant life stage, which shows contributions around $20 \%$ to all impact categories. Land use is attributed by more than $50 \%$ to the production of shampoo ingredients and only by $10 \%$ to the use phase. For all investigated impact categories, the results for the end-of-life phase of packaging materials are negligible compared to those of the other life phases and, therefore, have been included in the packaging production phase in Figure 1.

The most relevant processes within each life phase are highlighted Table 3 and are discussed in more detail in the following sections. 


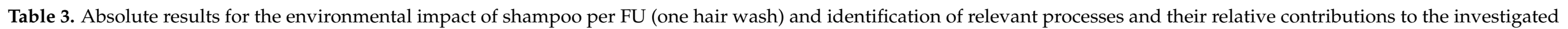

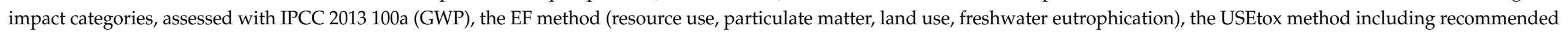
and interim characterization factors (freshwater ecotoxicity, human toxicity), and the ecological scarcity method (overall environmental impact).

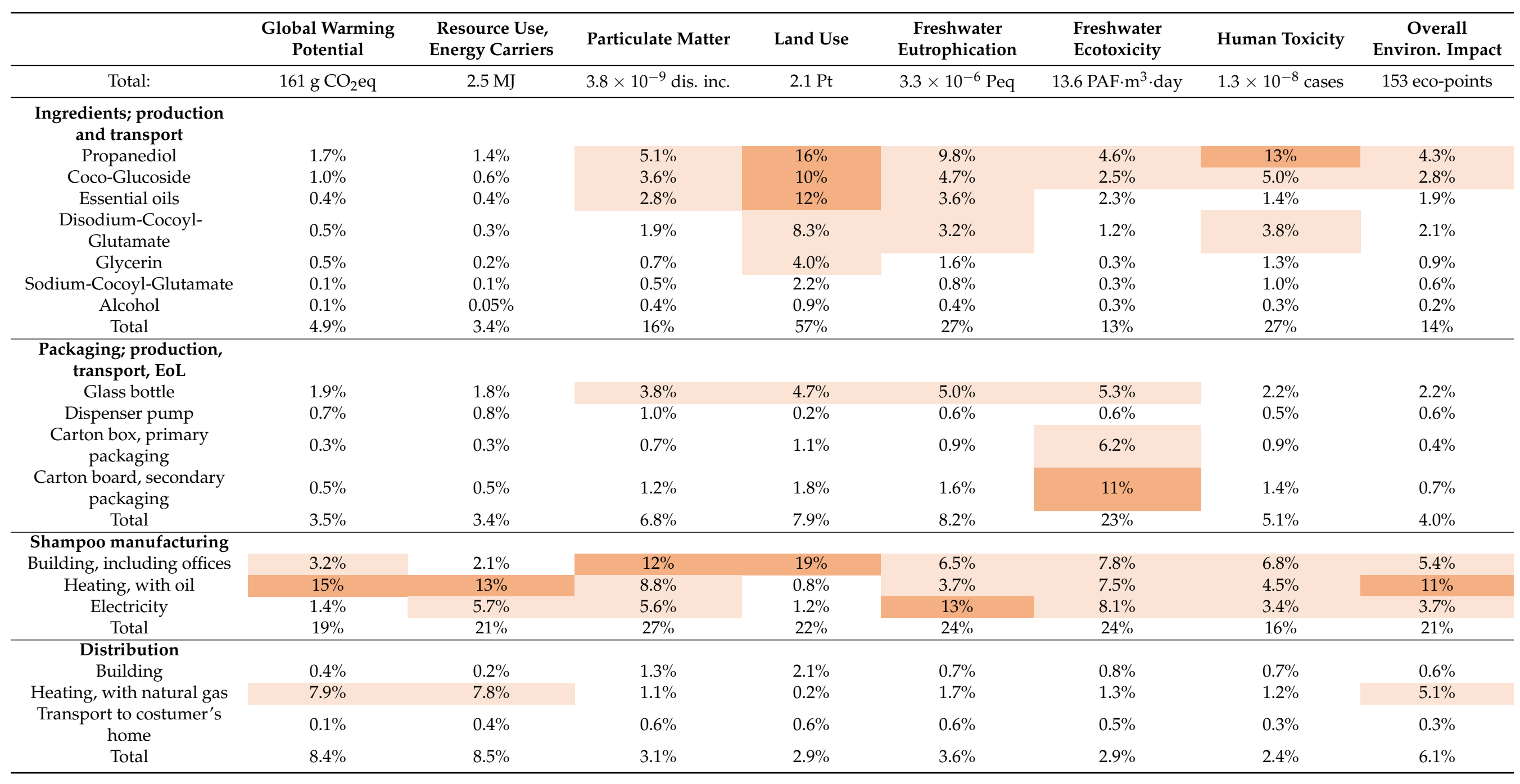


Table 3. Cont

\begin{tabular}{|c|c|c|c|c|c|c|c|c|}
\hline & $\begin{array}{c}\text { Global Warming } \\
\text { Potential }\end{array}$ & $\begin{array}{c}\text { Resource Use, } \\
\text { Energy Carriers }\end{array}$ & Particulate Matter & Land Use & $\begin{array}{c}\text { Freshwater } \\
\text { Eutrophication }\end{array}$ & $\begin{array}{l}\text { Freshwater } \\
\text { Ecotoxicity }\end{array}$ & Human Toxicity & $\begin{array}{c}\text { Overall } \\
\text { Environ. Impact }\end{array}$ \\
\hline \multicolumn{9}{|l|}{ Use phase } \\
\hline Heat, from natural gas & $34 \%$ & $34 \%$ & $4.6 \%$ & $0.7 \%$ & $7.6 \%$ & $5.9 \%$ & $5.3 \%$ & $22 \%$ \\
\hline Heat, from oil & $25 \%$ & $23 \%$ & $16 \%$ & $1.4 \%$ & $11 \%$ & $15 \%$ & $10 \%$ & $20 \%$ \\
\hline Heat, from wood chips & $0.05 \%$ & $0.05 \%$ & $12 \%$ & $6.5 \%$ & $0.2 \%$ & $2.5 \%$ & $2.1 \%$ & $0.5 \%$ \\
\hline Heat, using heat pump & $0.7 \%$ & $1.8 \%$ & $2.1 \%$ & $0.4 \%$ & $5.5 \%$ & $3.0 \%$ & $1.5 \%$ & $1.5 \%$ \\
\hline Water use & $1.4 \%$ & $2.4 \%$ & $6.0 \%$ & $1.0 \%$ & $5.6 \%$ & $5.6 \%$ & $21 \%$ & $4.0 \%$ \\
\hline Total & $62 \%$ & $61 \%$ & $42 \%$ & $10 \%$ & $31 \%$ & $33 \%$ & $44 \%$ & $49 \%$ \\
\hline \multicolumn{9}{|l|}{ Product EoL } \\
\hline Wastewater treatment & $1.8 \%$ & $1.5 \%$ & $5.0 \%$ & $0.8 \%$ & $6.3 \%$ & $4.4 \%$ & $5.2 \%$ & $6.4 \%$ \\
\hline \multirow[t]{2}{*}{ Total } & $1.8 \%$ & $1.5 \%$ & $5.0 \%$ & $0.8 \%$ & $6.3 \%$ & $4.4 \%$ & $5.3 \%$ & $6.4 \%$ \\
\hline & & & & scale: & $2.5-10 \%$ & $10-20 \%$ & $20-30 \%$ & $>30 \%$ \\
\hline
\end{tabular}




\subsubsection{Ingredients Production}

The production of ingredients turns out to be most relevant with respect to land use, to which it contributes by $57 \%$, while its contributions to other indicators vary between $3.4 \%$ for resource use of energy carriers and $27 \%$ for freshwater eutrophication. The high contribution to land use is caused by the fact that all ingredients are plant-based and, therefore, connected to cultivation of raw materials.

Propanediol and coco-glucoside as the main shampoo ingredients show the highest contributions to all impact indicators: Combined, they are responsible for about $50 \%$ of the environmental impact of the whole ingredients production phase. The provision of essential oils shows disproportionately high contributions, considering that they make up less than $0.5 \mathrm{w} \%$ of the shampoo. The main reason for this is the low yield withing the extraction of essential oils, leading to a high cultivation and energy demand. Furthermore, some of the used essential oils are transported from the production site to Switzerland via air, leading to a disproportionately high impact on climate change and resource use of energy carriers, while the transportation processes of the other ingredients show rather negligible contributions.

For all ingredients, the impact on climate change, resource use of energy carriers and particulate matter is mainly connected to the energy demand for cultivation and transformation processes. Drivers to freshwater eutrophication, freshwater toxicity, and human toxicity are mining of hard coal and lignite to cover the energy demand for manufacturing processes, mining of copper used in buildings as well as steel production for agricultural machinery and irrigation systems. Furthermore, freshwater eutrophication is partially caused by phosphate emissions from fertilizer use, freshwater toxicity is partially caused by heavy metal emissions (e.g., mercury and zinc emissions) from fertilizer use, and human toxicity is partially caused by copper emissions from plant protection products based on copper oxide for the cultivation of raw materials such as maize, coconut, and citrus.

With respect to the overall environmental impact according to the ecological scarcity method, the ingredients production makes up $14 \%$ of the whole life cycle and is primarily related to water pollutants, global warming and main air pollutants and particulate matter.

\subsubsection{Packaging Production and End-of-Life}

From a life cycle perspective, the shampoo packaging has the highest contribution to freshwater ecotoxicity (23\%). Its contributions to all other investigated impact indicators are between 3 to about $8 \%$.

Within the life phase itself, the production of the glass bottle represents the most relevant process, the main driver for most indicators being the energy demand of glass production processes. The glass bottle even shows a relatively high contribution to land use. Here, the main drivers are wood pallets and cardboard for transportation, both being based on wood as raw material. Freshwater ecotoxicity is the only impact indicator, which is not primarily related to the glass bottle, but rather to the carton board used both for primary and secondary packaging. This is due to high characterization factors attributed to sludge as residual from carton board production.

Due to high recycling rates in Switzerland for glass (94\%) and cardboard (82\%), the disposal of the packaging, i.e., its end-of-life phase, shows only minor contributions throughout all impact indicators and is, therefore, not listed among the relevant processes in Table 3.

The overall environmental impact of the packaging is mainly related to global warming as well as main air pollutants and particulate matter, reflecting the relevance of energy demand within this life phase.

\subsubsection{Shampoo Manufacturing}

The shampoo manufacturing shows consistent contributions of 16 to $27 \%$ to all impact categories. It contains three similarly relevant processes: the manufacturing building, heating of this building, and electricity demand. 
The manufacturing building has the highest contribution of $19 \%$ to land use, which is mainly caused by the utilization of wood as building material. The main driver for its impact on particulate matter and freshwater ecotoxicity is the electricity demand for aluminum production. Regarding heating of the manufacturing building, oil as energy source shows the highest contributions of about $15 \%$ to climate change and resource use of energy carriers. The refinery process of oil is mainly responsible for the contribution to particulate matter, while drilling waste is responsible for the contribution to freshwater ecotoxicity. Regarding the electricity demand, the import of electricity based on coal is the main driver for its contributions to freshwater eutrophication, freshwater ecotoxicity and particulate matter. In contrast to this, the contribution to resource use of energy carriers is mainly due to the high share of nuclear energy in Switzerland and the corresponding resource depletion of uranium.

The overall environmental impact of the manufacturing phase accounts for $21 \%$ of the whole life cycle impact. The most important impact categories within the manufacturing phase are global warming as well as main air pollutants and particulate matter.

\subsubsection{Distribution}

Heating the shop building with natural gas is the most relevant process within the distribution phase, particularly regarding climate change $(7.9 \%)$ and resource use of energy carriers $(7.8 \%)$.

Unlike the manufacturing building, the shop building is not among the most relevant processes. The cubage of the shop building per unit shampoo is about $10 \%$ of the cubage of the manufacturing building, considering the different building sizes as well as the yearly production volume and the yearly sales volume, respectively. Since the same generic ecoinvent dataset is used for both buildings, the environmental impact of the shop building has the same main drivers as the one of the manufacturing building but reaches proportionally smaller values for all indicators.

In contrast to the manufacturing phase, the electricity consumption of the shop has a negligible environmental impact and is, therefore, not listed in Table 3. One reason for this is the eco-friendly electricity product used for the shop, which is not based on the Swiss market mix but is mainly based on hydropower. Another reason is the lower electricity consumption per unit shampoo.

Compared to other processes within the distribution phase, the transportation from the shop to the consumer's home by trolleybus is of minor relevance, reaching the highest contributions of $0.6 \%$ to particulate matter, land use, and freshwater eutrophication. The contribution to particulate matter is caused by emissions during road construction and the electricity demand of the trolleybus, while freshwater eutrophication is mainly connected to the electricity demand of the trolleybus and land use is mainly caused by the direct land use of the road.

The overall environmental impact of the distribution phase is dominated by its impact on global warming.

\subsubsection{Use Phase}

The use phase is the most dominant life phase, with contributions of more than $60 \%$ to GWP and resource use of energy carriers. Its environmental impact, with exception of human toxicity, is almost entirely attributed to the energy provision for heating water. In this context, natural gas heating and oil heating represent two of the most relevant processes within the whole shampoo life cycle, showing the most significant contributions of $34 \%$ and $\sim 25 \%$, respectively, to climate change and resource use of energy carriers. In addition, the production of oil is the main driver for relevant contributions to particulate matter $(16 \%)$, freshwater ecotoxicity (15\%), and human toxicity $(10 \%)$. The contribution of oil heating to freshwater eutrophication $(11 \%)$ is related to copper used for the oil storage, more specifically to sulfidic tailings connected to copper mining. Heating with wood, which makes up only $0.1 \%$ of the assumed energy mix, is a significant contributor 
to particulate matter (12\%) and land use (6.5\%), while all other heating systems (district heating, heat pump, electricity, solar) have only minor to negligible contributions.

Human toxicity is the only indicator within the use phase, for which tap water provision shows an equally high contribution $(21 \%)$ as heat provision. This is due to slag from the production of cast iron used for the construction of the water supply network.

The overall environmental impact of the use phase makes up almost $50 \%$ of the impact of the whole life cycle. It is dominated by climate change caused by heating water with natural gas and oil.

\subsubsection{Product End-of-Life}

The product end-of-life phase contains two main processes: wastewater treatment and emissions of residual ingredients into water after wastewater treatment. However, the latter effects practically only human toxicity, and only to a negligible extent. Consequently, the environmental impact of the product end-of-life is almost entirely attributed to wastewater treatment, with a maximum contribution of 5.2\% to human toxicity. Most of the environmental impact within the wastewater treatment process is caused by the construction of infrastructure, namely the construction of sewer grid and of treatment facility.

With respect to the overall environmental impact, water pollutants are the main driver, followed by global warming, carcinogenic into air and main air pollutants and particulate matter.

\subsection{Comparison of Different Packaging and Refill Scenarios}

The results shown in the previous section refer to the packaging scenario 1, assuming shampoo is sold in a $500 \mathrm{~mL}$ glass bottle with a dispenser pump made of PE and PP. Summing all packaging related processes (production, transport, EoL), the global warming potential related to the shampoo packaging is $6 \mathrm{~g} \mathrm{CO}_{2} \mathrm{eq}$ per FU.

In the frame of this study, the potential environmental benefits of different refill options as specified in Table 2 were analyzed. The results are summarized in Figure 3 , which shows a relative comparison between all four packaging scenarios with respect to the considered impact indicators. The results contain resource use of minerals and metals as additional impact indicator, as it proves to be an environmental hotspot related to the production of tinplate.

In general, the production of PE and PET requires less energy than the production of glass and tinplate and at the same time leads to lower pollution due mining and metal processing. As a consequence, most impact indicators on midpoint level show a reduction between $20 \%$ and $50 \%$ for scenario 2 compared to scenario 1, and an even higher reduction between $50 \%$ and $90 \%$ for scenario 3 and 4 . Exceptions to this trend are resource use of minerals and metals, as well as human toxicity.

Regarding resource use of minerals and metals, the tinplate canister shows a higher impact than the glass bottle, increasing the result by almost $70 \%$. More than half of resource use of minerals and metals for the tinplate canister is related to tin, even though the assumed tin content of the canister is merely $0.02 \%$ and only $45 \%$ of the tin is primary material, while $55 \%$ is secondary material recovered from recycling processes.

Human toxicity forms another impact indicator for which the tinplate canister shows a higher impact than the glass bottle, leading to an about 30\% higher value. Here, steel and tin are equally responsible for the increase due to pollution connected to metal and coal mining.

No recycling is considered for the packaging end-of-life of scenarios 3 and 4, which means that both PE canister and PET stand-up pouch are assumed to be disposed via municipal incineration, while high recycling rates are assumed for glass (94\%) and tinplate $(82 \%)$. The incineration of PE and PET leads to considerable emissions of $\mathrm{CO}_{2}$, which explains why the decrease for global warming potential is less than for other midpoint indicators. In fact, sending both packaging to be recycled instead of incinerated would increase the GWP reduction for scenario 3 and 4 to 75 to $80 \%$ compared to scenario 1 . 
A major part of land use connected to the glass bottle is caused by wood pallets and cardboard for transportation, which are included in the ecoinvent-3.5 dataset for packaging glass. In contrast, the datasets used of tinplate, PE, and PET do not contain wood pallets or cardboard, which explains the decrease in land use for scenarios 2, 3, and 4 .

Comparing the PE canister and PET stand-up pouch, the PET pouch leads to lower values for GWP, particulate matter, and resource use of energy carriers. This is mainly because less material per unit shampoo is needed using a PET pouch compared to a PE canister. On the other hand, PE canisters can be distributed without secondary packaging, while PET pouches are distributed in cardboard boxes. Therefore, PE canisters perform better with respect to freshwater eutrophication, freshwater ecotoxicity, and human toxicity.

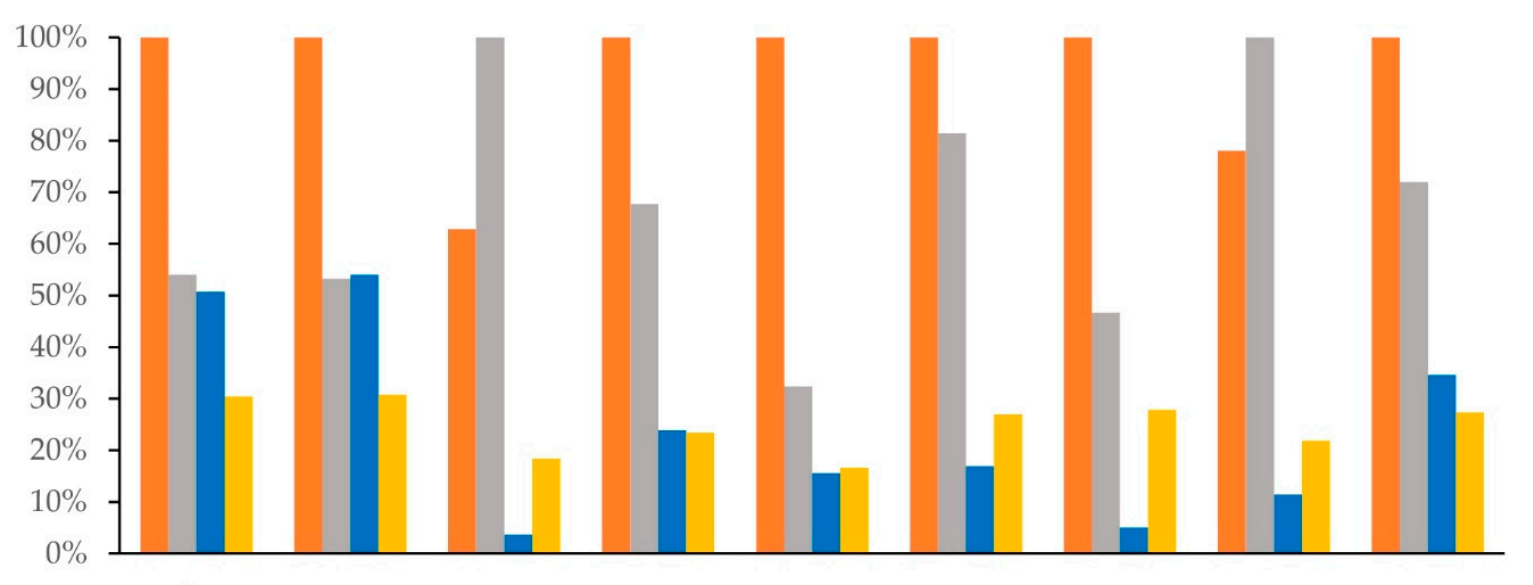

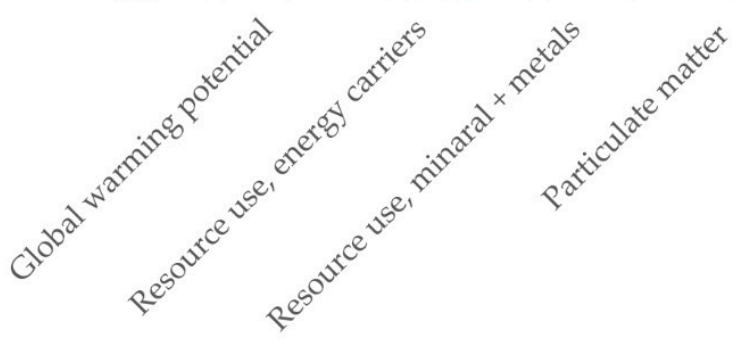

- Scenario 1: 500mL glass bottle

- Scenario 3: refill from 25L PE canister

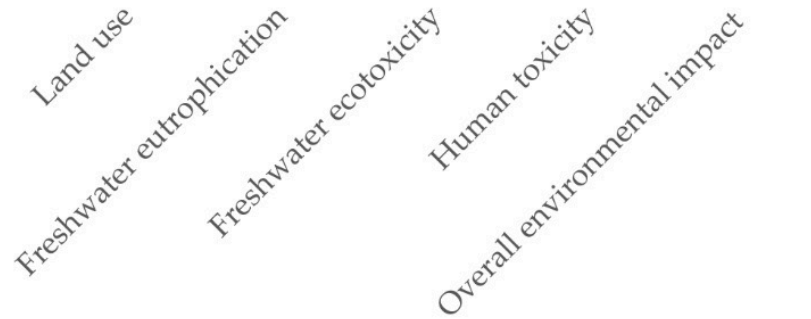

- Scenario 2: refill from 5L tinplate canister

- Scenario 4: refill from 500mL PET stand-up pouch

Figure 3. Comparison of different packaging scenarios per hair wash. The results shown refer only to packaging related processes (production, transportation, packaging EoL) and are based on IPCC 2013 100a (GWP), the EF method (resource use, particulate matter, land use, freshwater eutrophication), the USEtox method including recommended and interim characterization factors (freshwater ecotoxicity, human toxicity), and the ecological scarcity method (overall environmental impact).

The overall environmental impact of the shampoo packaging is cut by about $30 \%$ offering a refill option in the shop out of a $5 \mathrm{~L}$ tinplate canister (scenario 2). Refilling from a $25 \mathrm{~L} \mathrm{PE}$ canister (scenario 3) or selling $500 \mathrm{~mL}$ PET stand-up pouches (scenario 4) reduces the overall environmental impact even by about $70 \%$. Most of the reduction potential can be explained by a lower energy demand for the packaging production, as the production of glass bottles turns out be as highly energy consuming, as described above. The high impact on resource use of mineral and metals is the main reason why the tinplate canister does not reach the same reduction potential as the other two refill options, as both GWP and use of mineral resources have a high weight withing the ecological scarcity method.

\subsection{Sensitivity Analysis Concerning Use Phase}

The use phase emerges as the dominant life phases of the investigated shampoo, the main driver for its environmental impact being heating of shower water with natural gas and oil. 
As the shampoo is primarily sold on a local basis in Zurich, the energy mix of private households in Zurich as shown in Table 4 is assumed for heating water. The Zurich energy mix is based roughly one half on natural gas and one third on oil, with smaller shares of heat pumps and district heating and almost negligible shares of wood, electricity, and solar energy. In comparison, the national energy mix of Switzerland is more diverse, as also shown in Table 4, with only one third of oil, one quarter of natural gas, one quarter of electricity, and shares from 4.5 to $8.5 \%$ for all other energy sources.

Table 4. Average energy mix for heating water in Zurich [26] and in Switzerland [37].

\begin{tabular}{cccccccc}
\hline & $\begin{array}{c}\text { Natural } \\
\text { Gas }\end{array}$ & Oil & $\begin{array}{c}\text { District } \\
\text { Heating }\end{array}$ & $\begin{array}{c}\text { Heat } \\
\text { Pump }\end{array}$ & Wood & Electricity & Solar \\
\hline Zurich & $49.9 \%$ & $27.2 \%$ & $15.8 \%$ & $6.0 \%$ & $0.1 \%$ & $0.02 \%$ & $0.02 \%$ \\
Switzerland & $22.4 \%$ & $30.6 \%$ & $4.5 \%$ & $8.4 \%$ & $3,5 \%$ & $24.8 \%$ & $4.8 \%$ \\
\hline
\end{tabular}

Figure 4 shows the sensitivity of the environmental impact of the use phase towards the assumed energy mix. For the sensitivity study, the Zurich energy mix was replaced by the Swiss energy mix, while maintaining shower water quantity and temperature, i.e., keeping the energy consumption constant.
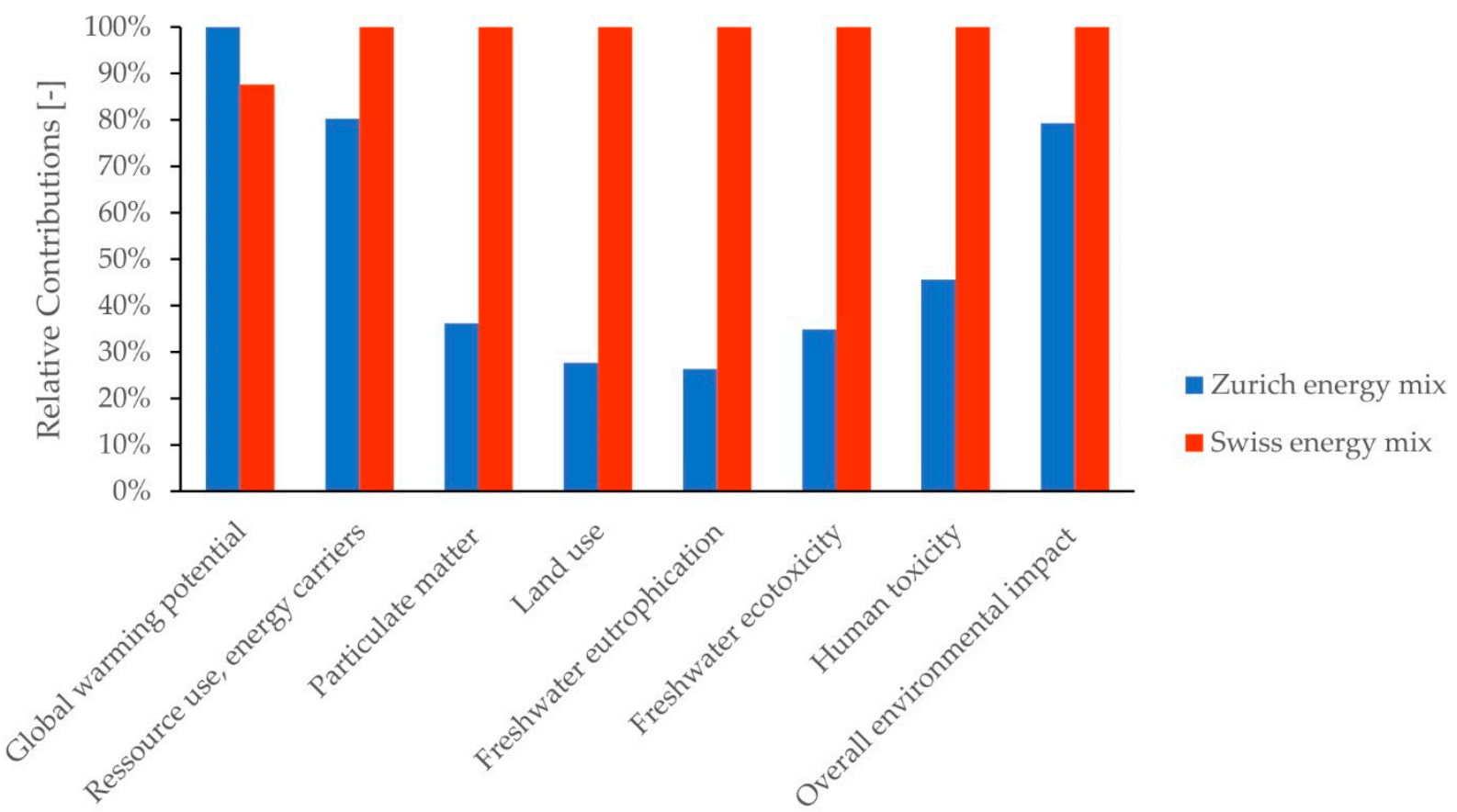

Figure 4. Sensitivity of environmental impact of shampoo towards the energy mix used for heating water for showering. Results shown refer to the use phase only, not to the entire life cycle of the shampoo, and are based on IPCC 2013 100a (GWP), the EF method (resource use, particulate matter, land use, freshwater eutrophication), the USEtox method including recommended and interim characterization factors (freshwater ecotoxicity, human toxicity), and the ecological scarcity method (overall environmental impact).

Using the Swiss energy mix instead of the Zurich energy mix increases the overall environmental impact by $20 \%$. However, this increase is not caused by an increase in GWP but instead by strong increases in other impact categories. In fact, the result for GWP shows a decrease of $12 \%$, which reflects the lower share of fossil fuels in the Swiss energy mix. For all other considered midpoint indicators, an increase can be observed. The much higher share of electricity in the Swiss energy mix is responsible for an increase of $25 \%$ with respect to resource use of energy carriers, considering the high share of nuclear energy in 
Switzerland. Imported electricity based on coal leads to significantly higher contributions to freshwater eutrophication, freshwater ecotoxicity, and human toxicity, the Swiss energy mix reaching values about two to four times higher than the Zurich energy mix. The same increase can be seen for particulate matter and land use, the main driver in these cases being the higher share of wood in the Swiss energy mix.

Given the high share of fossil-based heating in Zurich, global warming is the main contributor to the overall environmental impact of the use phase. The key parameter with respect to global warming is the energy demand for heating water, which is determined by the amount of shower water on the one hand and the water temperature, or more precisely the heat-up interval, on the other hand. In this study, a water consumption of $15 \mathrm{~L}$ and a heat-up interval of $23^{\circ} \mathrm{C}$ is assumed. Within a sensitivity study, two additional water quantities $(10 \mathrm{~L}, 20 \mathrm{~L})$ as well as two additional heat-up intervals $\left(19^{\circ} \mathrm{C}, 27^{\circ} \mathrm{C}\right)$ are considered. Figure 5 shows the resulting GWP of the use phase for all nine possible combinations, in each case assuming the Zurich energy mix for heating water. For the basic assumption of $15 \mathrm{~L}$ water heated up by $23^{\circ} \mathrm{C}$, the shampoo use phase is connected to a GWP equivalent to $100 \mathrm{~g} \mathrm{CO}_{2}$ eq. The most climate friendly shower behavior of the considered cases $\left(10 \mathrm{~L}\right.$ water, heat-up interval $19^{\circ} \mathrm{C}$ ) reduces this value by $40 \%$, while the most climate intensive shower behavior $\left(20 \mathrm{~L}\right.$ water, heat-up interval $\left.27^{\circ} \mathrm{C}\right)$ leads to an increase of $60 \%$.

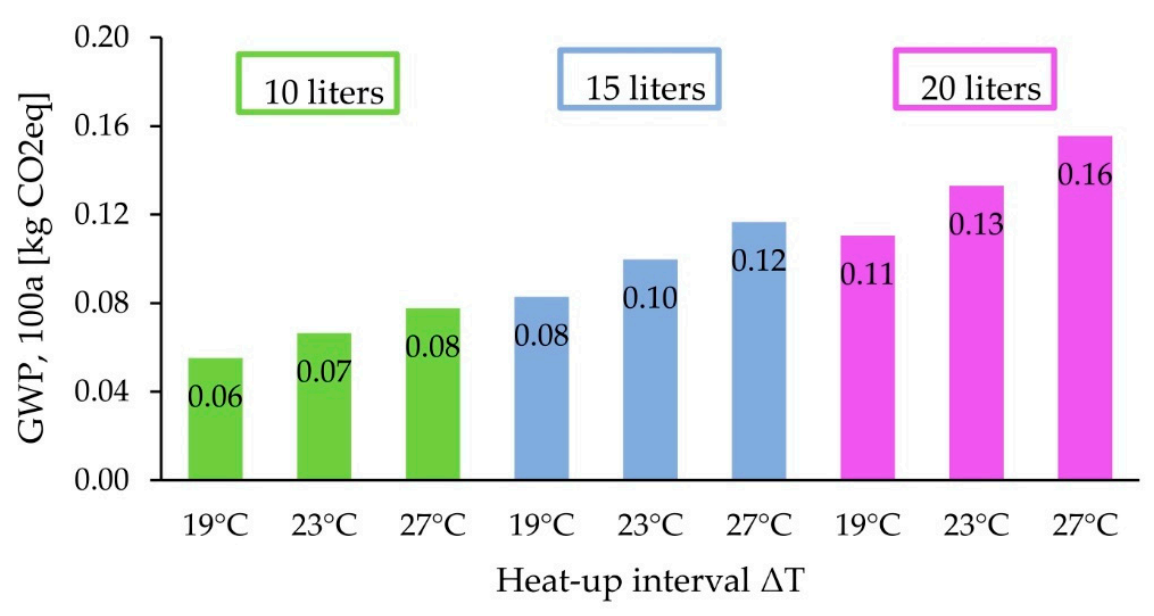

Figure 5. Sensitivity of global warming potential (GWP) based on IPCC 2013 100a per hair wash towards shower water quantity and water temperature. Results shown refer to the use phase only.

\section{Discussion}

In order to put the results of this study into context, limitations of the study, comparison to published data, and possibilities to mitigate the environmental burden of shampoo are discussed in the following sections.

\subsection{Considerations on Data Quality, Limitations and Research Recommendations}

Foreground data was provided by the manufacturer regarding shampoo ingredients, packaging and transportation, energy consumptions at the manufacturing site and at the point of sale, building sizes as well as production and sales volumes. The quality of the foreground data is considered high. However, the following limitations and uncertainties must be taken into account when interpreting the results of this study.

A major challenge consisted in modelling the ingredients within the life cycle inventory. Ecoinvent-3.5 datasets were available for glycerin, alcohol, and citric acid. All other ingredients except essential oils were modelled using datasets of intermediate products, such as glucose for Propanediol or sugar beet molasse and fatty acid for Disodium Cocoyl Glutamate. In these cases, assumptions had to be made regarding yields and energy consumption when converting intermediate products to final ingredients. 
The investigated shampoo contained more than ten different types of essential oils. Due to the lack of data concerning cultivation and production processes, all essential oils were modelled using the life cycle inventory of orange oil production in Italy, as published in [23]. This approach was justified as $60 \mathrm{wt} \%$ of the essential oils were citrus based. However, it can be assumed that specific parameters such yields and energy consumption for processing are not representable for the remaining $40 \mathrm{wt} \%$ of essential oils, which are mainly based on flowers and spices.

With respect to buildings, specific cubatures per kg shampoo produced and sold, respectively, were derived from the foreground data. However, only a generic ecoinvent dataset for multi-story buildings was used for modelling, applying the average lifespan of 80 years used in the dataset. Furthermore, production and sales volumes fluctuate over time. Consequently, contributions to the environmental impact connected to manufacturing building and shop building can be expected to vary significantly depending on the timeframe of the life cycle assessment. This is particularly important regarding the manufacturing phase, where the building emerges as relevant parameter for various impact categories.

The use phase, which is found dominant regarding climate change and resource use of energy carriers, is connected to high uncertainties as well. Here, the results strongly depend on assumptions made concerning the consumers' showering behavior as well as the energy source used for heating water, as sensitivity studies carried out in this study show. In addition, the reference flow itself is connected to high uncertainties. The amount of $9.5 \mathrm{~g}$ shampoo per hair wash represents an average value for German consumers. However, showering behavior and the actual amount of shampoo consumed for one hair wash are a highly subjective as they depend on individual preferences and characteristics, such as gender, age, hair length, and hair wash frequency [21,38].

With respect to freshwater ecotoxicity and human toxicity, results shown in this study are based on the USEtox method using both recommended and interim characterization factors. While this approach is recommended by experts [39], it is important to keep in mind that interim characterization factors do not fully meet the quality requirements of the method and are associated with uncertainties. Even including interim characterization factors, this study considers emissions of ingredient into water after wastewater treatment only for a limited number of ingredients, as for many ingredients there are no characterization factors available. In these cases, it is not clear whether characterization factors are still missing or whether they are not needed, as some ingredients might not of any considerable toxic impact. Furthermore, generic assumptions on removal rates at the wastewater treatment facility are taken from [4], as no specific removal rates are available. In this sense, further research is recommended to obtain reliable characterization factors and ingredient-specific removal rates in order to evaluate shampoo compositions with respect to freshwater ecotoxicity.

Finally, more LCA studies on personal care products should be carried out with respect to different geographic areas as the results strongly depend on energy mixes used for heating and for electricity. Regarding developing countries, household connectivity to wastewater treatment and waste collection as well as treatment procedures are additional relevant parameters that impact the contributions of the product and packaging end-of-life phases to the environmental impact. Furthermore, personal care products produced and sold outside Europe might contain ingredients with high health and environmental impact that are not approved for the European market.

\subsection{Comparison to Literature}

One of the most comprehensive LCA studies for shampoo was carried out by Cosmetics Europe and Quantis [4,5]. The LCA was carried out in the frame of a screening study to investigate the feasibility and relevance of establishing Product Environmental Footprint Category Rules (PEFCR) for shampoo, following the guidelines from the European Commission's Product Environmental Footprint (PEF) pilot phase [40]. The study 
referred to the functional unit of one hair wash and used a cradle-to-grave approach. A representative shampoo for the European market was assumed. As such, the main ingredients of the shampoo formula were sodium laureth sulfate and cocamidopropyl betaine, and the primary packaging consisted of a bottle made from polyethylene (PE). Average European energy mixes were used for electricity and heating, and large-scale production and distribution were assumed.

Concerning the use phase, this study confirms the results found by Quantis. In both studies, the use phase represents the dominant life stage, especially with respect to climate change. Furthermore, both studies find high sensitivities towards the energy mix used for heating water as well as the consumers habits while showering.

With respect to the manufacturing phase, however, Quantis concludes that this phase is not among the most relevant life stages, which is not in line with the results of this study. The reason for this discrepancy is most likely the manufacturing building infrastructure, which was not modelled by Quantis [4] and which this study highlights as one of the main drivers within the manufacturing phase. Quantis even concludes that the building does not represent a relevant parameter and, therefore, does not have to be included in the product systems. A possible reason for the different conclusions is different sales volumes. The shampoo investigated in this study is produced by a small manufacturer that produces personal care products batchwise on demand and not in a continuous way. Consequently, the use of infrastructure such as buildings is less efficient compared to big-scale manufacturers.

Another difference between the two studies are the results for freshwater ecotoxicity. This study finds the use phase as main contributor, followed by packaging production and shampoo manufacturing. In contrast, Quantis finds the end-of-life phase of shampoo almost entirely responsible for freshwater ecotoxicity. The reason for this discrepancy appears to be that the ingredients of the conventional shampoo analyzed by Quantis are connected to much higher characterization factors for ecotoxicity than the purely plantbased ingredients considered in this study. Especially sodium laureth sulfate, which is the main surfactant in the representative shampoo assumed by Quantis, is attributed with high characterization factors. However, it is important that results based on USEtox interim characterization factors are not used for product comparison due to their high uncertainties. Another reason for different results with respect to freshwater ecotoxicity might be that with respect to the end-of-life phase of the product, this study only takes into account emissions of ingredients for which interim or recommended characterization factors exist, while proxies are used for missing values within [4].

In general, a quantitative comparison between the studies proves to be difficult, as the investigated product systems are not entirely consistent, apart from the fact that only few absolute results are published in [4]. In addition, key parameters such as energy mix for heating and electricity mix differ, as this study refers to the city of Zurich while average European values are used in [4]. Besides this, also the reference flows used in the two studies differ, which makes the comparison in absolute terms challenging.

\subsection{Recommendations to Mitigate Environmental Impact of Shampoo}

\subsubsection{Use Phase}

The main environmental hotspot of the shampoo life cycle is the use phase, the environmental impact of which is mainly determined by the energy demand for heating water. In the medium or long term, clearly a change to more sustainable heating systems such as district heating, heat pumps, or solar thermal energy will reduce the impact of the use phase. On a more direct and individual level, the results of this study show that consumers can mitigate the environmental burden of their hair wash drastically in reducing shower water quantity and temperature. Adopting a climate friendlier showering habit can reduce the total GWP of the use phase by $40 \%$, taking a water consumption of $15 \mathrm{~L}$ heated up from 15 to $38{ }^{\circ} \mathrm{C}$ as reference and assuming the current Zurich energy mix. Assuming a hair wash each second day, this leads to total saving of $7.3 \mathrm{~kg} \mathrm{CO}_{2} \mathrm{eq}$ per year 
and consumer. From the shampoo manufacturer's perspective, a customer information campaign could be carried out to raise awareness for the influence of showering habits on the environmental impact of shampoo.

\subsubsection{Manufacturing and Distribution}

Next to the use phase, the manufacturing phase represents another relevant life phase of the investigated shampoo. Here, the relevant parameters are building, heating, and electricity consumption.

The manufacturing building is not among the parameters that can be easily changed. In addition, it is not easy to quantify mitigation potentials, considering the rather generic modelling of the building in this study and the fluctuating character of production volume. However, if the manufacturer changes production site, the results of this study show that it is important to use building space as efficiently as possible, i.e., to not occupy more building space than necessary.

The heating of the manufacturing building is currently based on oil and is responsible for $15 \%$ of the total GWP of one hair wash. This value could be drastically reduced in changing to a fossil-free heating system.

With respect to the electricity demand, the Swiss market mix is assumed in this study. Due to the import of electricity based on coal, this leads to relatively high contributions to particulate matter, freshwater eutrophication and freshwater ecotoxicity, while the high share of nuclear energy in Switzerland leads to a high contribution for resource use of energy carriers. A switch to an eco-friendly electricity product that neither contains coal nor nuclear energy would reduce these contributions.

The distribution phase is not among the most relevant life phases. However, contributions of almost $8 \%$ to climate change and resource use of energy carriers due to natural gas heating can be cut substantially by switching to a fossil-free heating system.

\subsubsection{Packaging Production and End-of-Life}

From a life cycle perspective, packaging is not among the environmental hotspots of the investigated shampoo. Nonetheless, this study shows that offering refill options represents an ecologically worthwhile measure, especially since it is relatively easy to implement as the investigated shampoo is mainly sold on a regional market in companyowned stores.

Among the investigated refill options, PE canisters and PET stand-up pouches appear more favorable than tinplate canisters, as the latter are highly compromised by the environmental impact related to tin and steel. Based on this study, refilling from a 25 LPE canister or a PET stand-up pouch instead of purchasing a new glass bottle of shampoo reduces the GWP connected to the shampoo packaging by about $70 \%$ and the GWP of the entire shampoo life cycle by about $2.5 \%$. With respect to freshwater eutrophication of the entire life cycle, the corresponding mitigation potential rises to even $12 \%$.

One of the guiding principles of the shampoo manufacturer consists in minimizing the use of plastic materials. The analyzed $500 \mathrm{~mL}$ PET stand-up pouch weights $10.22 \mathrm{~g}$ while the PE and PP parts of the dispenser pump sold with the $500 \mathrm{~mL}$ glass bottle weight $10.84 \mathrm{~g}$. Consequently, refilling the glass bottle from a PET stand-up pouch even reduces the amount of plastic used per unit shampoo.

For a $25 \mathrm{~L}$ PE canister, disposal via municipal incineration makes up about half of the GWP of packaging relevant processes. Therefore, another measure to mitigate packaging related burdens even further is the recycling of refill canisters. Re-using the canister is another measure with high reduction potential, even though in this case, the water and energy demand for rinsing the canister after use would need to be taken into account.

\subsubsection{Ingredients Production and End-of-Life}

Avoiding petrol-based ingredients being among the manufacturer's guiding principles, all ingredients of the investigated shampoo are based on agricultural products, such 
as maize and coconut. This explains the high contribution to land use from the ingredient production phase. Other burdens connected to the cultivation of raw materials are freshwater eutrophication and ecotoxicity due to the use fertilizers and pesticides. Some ingredients of the shampoo can be derived based on various raw materials using different processes, e.g., propanediol [41]. This means, choosing suppliers that use raw materials and processes with a comparatively low environmental impact could help to reduce the ecological footprint of the shampoo, without changing its composition. Environmental impacts from the cultivation of raw materials can also be reduced by applying more sustainable agricultural practices. For example, field experiments show that phosphate emissions in surface runoff from maize cultivation could be significantly decreased without reducing plant nutrient uptake by simply reducing the amount of phosphate fertilizer application by up to $50 \%$ compared to conventional fertilizing [42]. An overview of clean technologies in agriculture and how to prioritize them from a sustainability perspective was published by Scharfy et al. [43]. New incentives for a more sustainable production of raw materials can be anticipated from policies within the European Green Deal strategy that sets ambitious goals "and will require a complex, multi-threaded approach to agricultural policy and a change in the attitude of farmers" [44]. Globally, about 50 countries have introduced bioeconomy related policy strategies in the past decade and it is important that the promotion of bio-based materials also addresses sustainability concerns related to food security and the protection of natural resources [45].

\section{Conclusions}

Assessing the environmental impact of a natural shampoo with a cradle-to-grave approach, the use phase and the manufacturing phase emerge as most relevant life stages. Due to water heating based on fossil fuels, the use phase shows major contributions to climate change and resource use of energy carriers. Consumers can reduce these burdens significantly in adopting more climate friendly shower habits, such as using less water and reducing the water temperature. On the manufacturer side, ecological hotspots are oil-based heating, the manufacturing building, and electricity consumption. Switching to renewable energy sources both for heating and electricity can reduce the environmental impact of the manufacturing phase, especially with respect to climate change and resource use of energy carriers. Regarding the building, reduction measures are less obvious. Nonetheless, the results emphasize the importance of using building space in an efficient and responsible way.

The investigated shampoo is sold in glass bottles on a regional market. Glass as packaging material is comparably energy intensive, even when using recycled material. Consequently, offering refill options represents an effective measure, which can reduce the environmental impact of the shampoo life cycle by several percent. Among the analyzed refill scenarios, PE canisters and PET stand-up pouches show a lower environmental impact than tinplate canisters, as tin is environmentally compromised due to resource use and to harmful emissions during mining and processing.

With all shampoo ingredients being plant-based, land use forms an environmental hotspot with respect to ingredients production. At the same time, the results of the study suggest that freshwater ecotoxicity due to emission of ingredients at the product end-of-life is negligible and does not form an environmental hotspot of the shampoo. In this context, a need for robust characterization factors and for specific removal rates in wastewater treatment facilities is identified to fully assess the extent of freshwater ecotoxicity of shampoo ingredients.

In summary, the results of the LCA study show that the environmental impact of the investigated shampoo can be reduced by several percent with the help of refill offers. However, higher reduction potentials exist on the producer's as well as on the consumer's side, especially by changing to renewable energy sources and by adapting shower habits.

Supplementary Materials: The following supplementary material is available online at https:/ /www. mdpi.com/article/10.3390/su13158478/s1, S1: Life cycle inventory of the investigated shampoo. 
Author Contributions: M.S. supervised the study and supported the publication with regular feedback. H.K. conducted the life cycle assessment and wrote the publication. Both authors have read and agreed to the published version of the manuscript.

Funding: This research received no external funding.

Data Availability Statement: Life cycle inventory data used in this study are available through the supplementary material (see above).

Conflicts of Interest: The authors declare no conflict of interest.

\section{References}

1. Ficheux, A.S.; Wesolek, N.; Chevillotte, G.; Roudot, A.C. Consumption of Cosmetic Products by the French Population. First Part: Frequency Data. Food Chem. Toxicol. 2015, 78, 159-169. [CrossRef] [PubMed]

2. Hall, B.; Tozer, S.; Safford, B.; Coroama, M.; Steiling, W.; Leneveu-Duchemin, M.C.; McNamara, C.; Gibney, M. European Consumer Exposure to Cosmetic Products, a Framework for Conducting Population Exposure Assessments. Food Chem. Toxicol. 2007, 45, 2097-2108. [CrossRef] [PubMed]

3. Koehler, A.; Wildbolz, C. Comparing the Environmental Footprints of Home-Care and Personal-Hygiene Products: The Relevance of Different Life-Cycle Phases. Environ. Sci. Technol. 2009, 43, 8643-8651. [CrossRef] [PubMed]

4. Quantis. PEF Shampoo Screening Report in the Context of the Study into the Development of Product Environmental Footprint Category Rules (PEFCR). Available online: https:/ / cosmeticseurope.eu/how-we-take-action/driving-sustainable-development (accessed on 20 May 2020).

5. Study into the Development of Product Environmental Footprint Category Rules for Shampoo; Quantis: Lausanne, Switzerland, 2016.

6. $\quad$ Escamilla, M.; Ferrer, A.; Fuentes, N.; Hidalgo, C.; Renata, K.; Kougoulis, J. Revision of European Ecolabel Criteria for Soaps, Shampoos and Hair Conditioners; Preliminary Results from the Technical Analysis (Draft); Joint Research Centre (JRC) of the European Commission: Brussels, Belgium, 2012.

7. Rebello, S.; Asok, A.K.; Mundayoor, S.; Jisha, M.S. Surfactants: Toxicity, Remediation and Green Surfactants. Environ. Chem. Lett. 2014, 12, 275-287. [CrossRef]

8. $\quad$ Bhadani, A.; Kafle, A.; Ogura, T.; Akamatsu, M.; Sakai, K.; Sakai, H.; Abe, M. Current Perspective of Sustainable Surfactants Based on Renewable Building Blocks. Curr. Opin. Colloid Interface Sci. 2020, 45, 124-135. [CrossRef]

9. Wiegmann, K.; Hünecke, K.; Moch, K.; Hennenberg, K.J.; Fehrenbach, H. Blauer Engel Biobasierte Produkte-Abschlussbericht Teil 4: PROSA Biobasierte Wasch- und Reinigungsmittel; Federal Environmental Agency (Umweltbundesamt, UBA): Dessau-Rosslau, Germany, 2019.

10. European Bioplastics. Bioplastics Market Data. Available online: https://www.european-bioplastics.org/market/ (accessed on 13 June 2020).

11. Tasaki, T.; Yamakawa, H. An Estimation of the Effectiveness of Waste Prevention by Using Point-of-Sales (POS) Data-The Case of Refills for Shampoo and Hair Conditioner in Japan. Resour. Conserv. Recycl. 2011, 57, 61-66. [CrossRef]

12. Coelho, P.M.; Corona, B.; ten Klooster, R.; Worrell, E. Sustainability of Reusable Packaging-Current Situation and Trends. Resour. Conserv. Recycl. X 2020, 6, 100037. [CrossRef]

13. Kunamaneni, S.; Jassi, S.; Hoang, D. Promoting Reuse Behaviour: Challenges and Strategies for Repeat Purchase, LowInvolvement Products. Sustain. Prod. Consum. 2019, 20, 253-272. [CrossRef]

14. Branska, L.; Patak, M.; Hromadnikova, K.; Pecinova, Z. Sales of Consumer Chemicals in Zero-Packaging Stores-A Challenge for Small and Medium-Sized Chemical Companies. Hradec Econ. Days 2021, 11, 98-106. [CrossRef]

15. Haerulloh, A.A.; Hiwari, H. Bulk Store as an Effort to Reduce Marine Debris in Bajo Pulau. J. Perspekt. Pembiayaan Dan Pembang. Drh. 2020, 8, 475-486. [CrossRef]

16. Boesen, S.; Bey, N.; Niero, M. Environmental Sustainability of Liquid Food Packaging: Is There a Gap between Danish Consumers' Perception and Learnings from Life Cycle Assessment? J. Clean. Prod. 2019, 210, 1193-1206. [CrossRef]

17. Dinkel, F.; Kägi, T. Ökobilanz Getränkeverpackungen, Gesamtbericht; Carbotech, A.G., Ed.; Federal Office for the Environment (FOEN): Bern, Switzerland, 2014.

18. Ferrara, C.; De Feo, G. Comparative Life Cycle Assessment of Alternative Systems for Wine Packaging in Italy. J. Clean. Prod. 2020, 259, 120888. [CrossRef]

19. ISO 14040:2006. Environmental Management_Life Cycle Assessment_Principles and Framework; International Organization for Standardization: Geneva, Switzerland, 2009.

20. SimaPro. PRéConsultants, Amersfoort, The Netherlands. Available online: https://pre-sustainability.com/solutions/tools/ simapro/ (accessed on 28 April 2021).

21. McNamara, C.; Rohan, D.; Golden, D.; Gibney, M.; Hall, B.; Tozer, S.; Safford, B.; Coroama, M.; Leneveu-Duchemin, M.C.; Steiling, W. Probabilistic Modelling of European Consumer Exposure to Cosmetic Products. Food Chem. Toxicol. 2007, 45, 2086-2096. [CrossRef] [PubMed]

22. Wernet, G.; Bauer, C.; Steubing, B.; Reinhard, J.; Moreno-Ruiz, E.; Weidema, B. The Ecoinvent Database Version 3 (Part I): Overview and Methodology. Int. J. Life Cycle Assess. 2016, 21, 1218-1230. [CrossRef] 
23. Beccali, M.; Cellura, M.; Iudicello, M.; Mistretta, M. Resource Consumption and Environmental Impacts of the Agrofood Sector: Life Cycle Assessment of Italian Citrus-Based Products. Environ. Manag. 2009, 43, 707-724. [CrossRef] [PubMed]

24. Google Maps. Available online: https:/ / www.google.ch/maps (accessed on 28 June 2020).

25. Stromkennzeichnung (Electricity Disclosure). Available online: https:/ / www.strom.ch/de/service/stromkennzeichnung (accessed on 23 October 2020).

26. Erneuerbare Energien auf dem Vormarsch; City of Zurich, Switzerland. Available online: https://www.stadt-zuerich.ch/prd/de/ index/statistik/publikationen-angebote/publikationen/webartikel/2017-08-21_Erneuerbare-Energien-auf-dem-Vormarsch. html\#energietraegermix2017 (accessed on 28 September 2020).

27. Doka, G. Life Cycle Inventories of Waste Treatment Services, Part IV Wastewater Treatment; Swiss Centre for Life Cycle Inventories: Duebendorf, Switzerland, 2003.

28. Abfallmengen und Recycling 2018 im Überblick; Federal Office for the Environment (FOEN): Bern, Switzerland, 2019.

29. Jordan, U.; Vajen, K. Realistic Domestic Hot-Water Profiles in Different Time Scales; Solar Heating and Cooling Program of the International Energy Agency (IEA SHC), Task 26: Solar Combisystems; University of Marburg: Marburg, Germany, 2001.

30. Climate Change 2013: The Physical Science Basis. In Contribution of Working Group I to the Fifth Assessment Report of the Intergovernmental Panel on Climate Change, IPCC; Cambridge University Press: Cambridge, UK, 2014.

31. Van Oers, L.; De Koning, A.; Guinée, J.B.; Huppes, G. Abiotic Resource Depletion in LCA; Road and Hydraulic Engineering Institute, Ministry of Transport and Water: Amsterdam, The Netherlands, 2002.

32. Fantke, P.; Evans, J.R.; Hodas, N.; Apte, J.S.; Jantunen, M.J.; Jolliet, O.; McKone, T.E. Health impacts of fine particulate matter. In Global Guidance for Life Cycle Impact Assessment Indicators: Volume 1; UNEP/SETAC Life Cycle Initiative: Paris, France, 2016; pp. 76-99, ISBN 92-807-3630-2.

33. Bos, U.; Horn, R.; Beck, T.; Lindner, J.P.; Fischer, M. LANCA ${ }^{\circledR}$-Characterization Factors for Life Cycle Impact Assessment: Version 2.0; Fraunhofer Verlag: Stuttgart, Germany, 2016; ISBN 3-8396-0953-4.

34. Struijs, J.; Beusen, A.; Van Jaarsveld, H.; Huijbregts, M.A.J. Aquatic Eutrophication. ReCiPe 2008 A Life Cycle Impact Assessment Method Which Comprises Harmonised Category Indicators at the Midpoint and the Endpoint Level. Report I Characterisation. 2009. Available online: https://www.leidenuniv.nl/cml/ssp/publications/recipe_characterisation.pdf (accessed on 9 June 2021).

35. Rosenbaum, R.K.; Bachmann, T.M.; Gold, L.S.; Huijbregts, M.A.J.; Jolliet, O.; Juraske, R.; Koehler, A.; Larsen, H.F.; MacLeod, M.; Margni, M.; et al. USEtox-The UNEP-SETAC Toxicity Model: Recommended Characterisation Factors for Human Toxicity and Freshwater Ecotoxicity in Life Cycle Impact Assessment. Int. J. Life Cycle Assess. 2008, 13, 532-546. [CrossRef]

36. Frischknecht, R.; Büsser Knöpfel, S.; Flury, K.; Stucki, M.; Ahmadi, M. Swiss Eco-Factors 2013 According to the Ecological Scarcity Method; Federal Office for the Environment (FOEN): Bern, Switzerland, 2013.

37. Kemmler, A.; Spillmann, T.; Piégsa, A.; Notter, B.; Cox, B.; Jakob, M.; Catenazzi, G. Analyse des Schweizerischen Energieverbrauchs 2000-2018 nach Verwendungszwecken; Swiss Federal Office of Energy (SFOE): Bern, Switzerland, 2019.

38. Ficheux, A.S.; Chevillotte, G.; Wesolek, N.; Morisset, T.; Dornic, N.; Bernard, A.; Bertho, A.; Romanet, A.; Leroy, L.; Mercat, A.C.; et al. Consumption of Cosmetic Products by the French Population Second Part: Amount Data. Food Chem. Toxicol. 2016, 90, 130-141. [CrossRef] [PubMed]

39. Golsteijn, L. How to Use USEtox®Characterisation Factors in SimaPro. Available online: https://pre-sustainability.com/articles/ how-to-use-usetox-characterisation-factors-in-simapro/ (accessed on 28 April 2021).

40. Golsteijn, L.; Lessard, L.; Campion, J.-F.; Capelli, A.; D’Enfert, V.; King, H.; Kremer, J.; Krugman, M.; Orliac, H.; Furnemont, S.R.; et al. Developing Product Environmental Footprint Category Rules (PEFCR) for Shampoos: The Basis for Comparable Life Cycle Assessment: Product Environmental Footprint Category Rules for Shampoos. Integr. Environ. Assess. Manag. 2018, 14, 649-659. [CrossRef]

41. Marktanalyse Nachwachsende Rohstoffe; Fachagentur Nachwachsende Rohstoffe e. V. (FNR): Gülzow-Prüzen, Germany, 2014; ISBN 978-3-942147-18-7.

42. Zhang, Y.; Xie, D.; Ni, J.; Zeng, X. Optimizing Phosphate Fertilizer Application to Reduce Nutrient Loss in a Mustard (Brassica Juncea Var. Tumida)-Maize (Zea mays L.) Rotation System in Three Gorges Reservoir Area. Soil Tillage Res. 2019, 190, 78-85. [CrossRef]

43. Scharfy, D.; Boccali, N.; Stucki, M. Clean Technologies in Agriculture-How to Prioritise Measures? Sustainability 2017,9 , 1303. [CrossRef]

44. Wrzaszcz, W.; Prandecki, K. Agriculture and the European Green Deal. Probl. Agric. Econ. 2020, 365, 156-179. [CrossRef]

45. Von Braun, J. Bioeconomy-The Global Trend and Its Implications for Sustainability and Food Security. Glob. Food Secur. 2018, 19, 81-83. [CrossRef] 